\title{
AN EXPERIMENTAL STUDY ON MULTI-PURPOSE DESICCANT INTEGRATED VAPOR-COMPRESSION AIR-CONDITIONING SYSTEM
}

\author{
Alsaied Khalil, Member ASHRAE \\ Mechanical Power Engineering Department, Faculty of Engineering, \\ Tanta University, Tanta, Egypt. akhalileg@yahoo.com
}

(Received August 11, 2009 Accepted December 17, 2009).

\begin{abstract}
In this paper, a multi-purpose hybrid desiccant integrated vapor compression air conditioning system of a small capacity is experimentally investigated. The system, referred as HDAC, is designed to meet the cooling load of spaces having large latent heat portions and at the same time to extract water from atmospheric air. The system is mainly consisted of a liquid desiccant dehumidification unit integrated with a vapor compression system (VCS). The dehumidification unit uses lithium chloride $(\mathrm{LiCl})$ solution as the working material. The effect of different parameters such as, desiccant solution flow rate, process air flow rate, evaporator and condenser temperatures, strong solution concentration and regeneration temperature on the performance of the system is studied. This system has a water recovery rate of $6.7 \mathrm{l} / \mathrm{h} . \mathrm{TR}$ of pure water at typical north Egyptian climate. The HDAC system has a COP as high as 3.8 (an improvement of about $68 \%$ over the conventional VCS. The system offers a total cooling capacity of about 1.75 TR using a 0.75 TR VCS unit. Finally, the proposed system is found to have a payback time of about 10 months without any considerable extra capital cost compared to the known split air conditioning system. The results emphasize the potential benefits of the HDAC system.
\end{abstract}

KEYWORDS: hybrid system, dehumidification, water recovery, vapor compression system, liquid desiccant, life cycle analysis.

\section{INTRODUCTION}

As the energy shortage emerges as an issue of growing concern in the world, coupled with the threat to environment posed by the conventional refrigerants, the need to come up with the new energy saving as well as environmentally friend air conditioning systems has been more urgent than ever before. The liquid desiccant dehumidification systems integrated with VCS driven by low-grade heat sources can partially meet those needs; meanwhile, they provide an ideal area for the application of waste heat discharged from local factories, and the employment of brine solutions as absorbent brings less damage to environment. A review of liquid-desiccant systems was done by [1]. Desiccant system using triethylene glycol integrated with VCS has long been adopted for both industrial and agricultural purposes, such as humidity control in textile mill and post harvest low-temperature crop-drying in stores, and is now taking a more prominent role in the air conditioning field. Its economical advantages and 
effective humidity control at low and moderate temperature really dwarfs the conventional method of humidity control, (generally, lowering the air temperature to below the dewpoint temperature). Adnan et al. [2] introduced an energy efficient system using liquid desiccant which is proposed to overcome the latent part of the cooling load in an air conditioning system. It can be concluded that the proposed system can be used effectively to reduce electric energy consumption in air conditioning to about 0.3 of the energy consumed by a conventional air conditioning system. Mohan et al. [3] studied the performance of absorption and regeneration columns for a liquid desiccant-vapor compression hybrid system. They reported that higher the specific humidity and lower the temperature of inlet air, higher will be the dehumidification in the absorber. Similarly, the regeneration can be increased by increasing the temperature and decreasing the specific humidity of inlet air to the regenerator. Jia et al. [4] introduced a hybrid desiccant-assisted air conditioner (HDAC) and split cooling coil system, which combines the merits of moisture removal by desiccant and cooling coil for sensible heat removal, which is a potential alternative to conventional vapor compression cooling systems. It is found that, compared with the conventional VCS with reheat, the HDAC system economizes $52.5 \%$ electric energy consumption.

\begin{tabular}{|c|c|c|c|}
\hline \multicolumn{4}{|c|}{ NOMENCLATURE } \\
\hline$C_{P}$ & $\begin{array}{l}\text { Specific Heat at const. pressure, } \\
\mathrm{kJ} / \mathrm{kg} . \mathrm{K}\end{array}$ & sol & Desiccant Solution \\
\hline$m$ & Mass Flow Rate, $\mathrm{kg} / \mathrm{s}$ & reg & Regeneration \\
\hline$Q$ & Heat Transfer Rate, $\mathrm{kW}$ & $w s$ & Weak Solution \\
\hline $\bar{T}$ & Air Temperature, ${ }^{\circ} \mathrm{C}$ & \multicolumn{2}{|c|}{ Abbreviations } \\
\hline$V$ & Volume Flow Rate, 1/min & $A H$ & Auxiliary Heating coil \\
\hline$w$ & Air Humidity Ratio, $\mathrm{kg}_{\text {vapor }} / \mathrm{kg}_{\text {air }}$ & COP & Coefficient Of Performance \\
\hline$x$ & Desiccant Solution Concentration, & $I A Q$ & Indoor Air Quality \\
\hline & $\mathrm{kg}_{\mathrm{d}} / \mathrm{kg}_{\text {sol }}$ & $\mathrm{LiCl}$ & Lithium Chloride \\
\hline \multicolumn{2}{|c|}{ Subscripts } & $L C S$ & Life Cycle Savings \\
\hline$a$ & Air & $S M R$ & $\begin{array}{l}\text { Specific Moisture Recovery, } \\
\mathrm{kg}_{\mathrm{vap}} / \mathrm{kg}_{\text {sol }}\end{array}$ \\
\hline$c c$ & Cooling Capacity & $V C S$ & Vapor Compression System \\
\hline$d$ & Desiccant & WRR & Water Recovery Rate, $1 / \mathrm{h}$ \\
\hline pre & Preheating & $P W F$ & Present Worth Factor \\
\hline ss & Strong Solution & $P P$ & Payback Period \\
\hline
\end{tabular}

Ahmed et al. [5] simulated a hybrid open-cycle absorption and liquid desiccant system using $\mathrm{LiBr}$ for the process of absorption and dehumidification. The simulation model of the hybrid cycle is formulated with a partly closed-open solar regenerator for regenerating the weak desiccant and a packed tower dehumidifier for the dehumidification of ambient air. The COP obtained is about 50\% higher than that of a conventional absorption machine. Investigation by Yadav [6] showed that the hybrid vapor compression system was more promising under high latent load or higher ambient humidity conditions, and significant energy saving can be achieved over the conventional VCS. Yadav and Kaushik [7] have studied a hybrid solid desiccant system. It was found that the system resulted in $25 \%$ energy saving over a VCS. Dai et 
al. [8] introduced a hybrid air conditioning system, which consists of a desiccant dehumidifier, evaporative cooling and vapor compression air conditioning. They found that the cooling production increased by $20-30 \%$ compared to the VCS alone, it is also found that the electric power consumption and size of vapor compression cycle can be further reduced. Burns et al. [9] studied three hybrid system configurations for supermarket applications (high latent load) and a comparison of their performance with conventional air-conditioning system was made. The cycles termed as ventilationcondenser cycle, recirculation-condenser cycle and ventilation-heat exchanger cycle. They reported that these cycles would give energy savings, in comparison to the conventional air-conditioning systems, ranging from 56.5 to 66\%. Close et al. [10] uses an energy weight as one unit of electrical energy weighted three that of thermal energy. Singh et al. [11] have analyzed the afore-mentioned three hybrid cycles, introduced in [9], for Indian climatic conditions. Modeling of the dehumidifier operating at a fixed regeneration temperature of $135^{\circ} \mathrm{C}$, and regeneration to process air area ratio of 0.33 is done using the performance data from a manufacturer. It is reported that energy savings ranging from $30 \%$ to $50 \%$ can be achieved at lower SHF.

In the present work, the HDAC system is designed to meet the needs of cooling, dehumidification, reducing energy consumption and extracting pure water from atmospheric air. This system is very suitable to be used in humid climates, places with high latent load components, such as supermarkets, theaters or auditoriums, and also suitable for places with scarcity of potable water, such as coastal areas, islands and workplaces inside oceans (e.g. oil fields). The proposed HDAC system is studied and the effects of the relevant operating parameters on the performance of the whole system are studied and analyzed from the thermal as well as economical point of view.

\section{THE HDAC SYSTEM}

A schematic diagram of the multi-purpose integrated HDAC system is shown in Fig. 1. The proposed system is mainly consisted of a liquid desiccant dehumidification unit integrated with a vapor compression system. The dehumidification unit uses lithium chloride $(\mathrm{LiCl})$ solution as the desiccant material. The psychometric process of the process air of the proposed system is shown in Fig. 2. This process is denoted by solid line; process 1-2. The dashed line 1-3-2 represents the equivalent conventional system (process 1-3 is cooling and dehumidification over the DX cooling coil and process 3-2 is reheating).

In Fig. 1, the desiccant strong solution of concentration $x_{8}$ is pumped and uniformly sprayed over the evaporator surface area. The process air stream at ambient state (1) is passed through the evaporator in cross flow scheme. The process air is then cooled and dehumidified to point (2). The desiccant weak solution is then collected and drawn to the weak solution tank (A). The weak solution (4) is then pumped to the heat exchanger (E) which uses the exhaust heat rejected from the condenser of the VCS to preheat the weak solution. An additional heat is required to completely regenerate the weak solution in the regenerator (B) to reach state (8). The water vapor exit from the regenerator at state (6) is collected and condensed to point (7). The condensate (pure water out) may be used for potable application. 


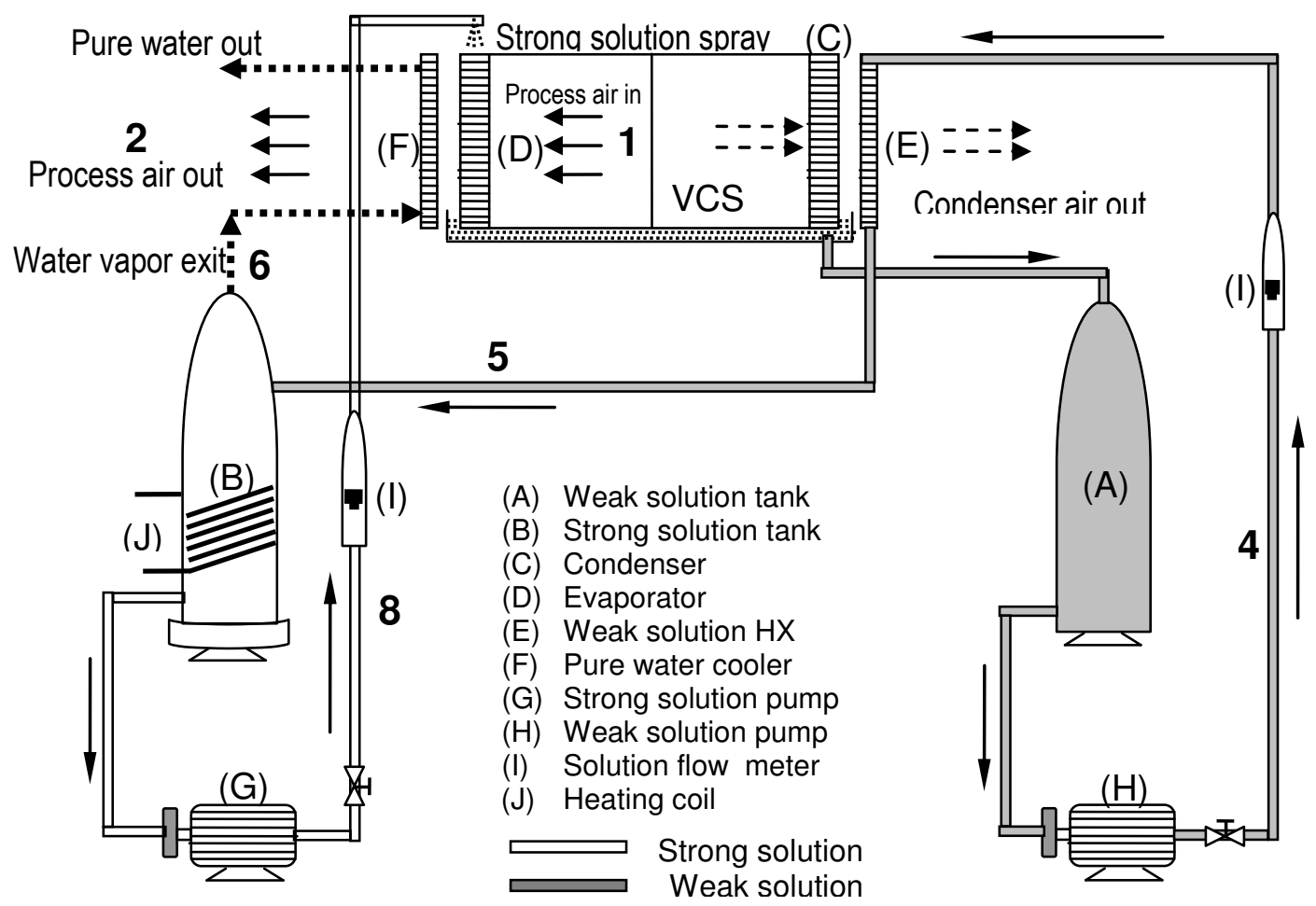

Fig. 1 Schematic diagram of the multi-purpose integrated HDAC system.

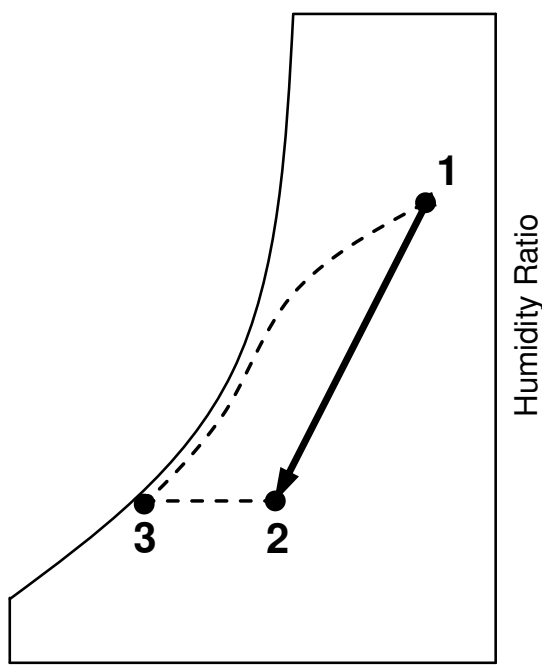

Dry Bulb Temperature

Fig. 2 Typical psychometric process of the proposed HDAC system.

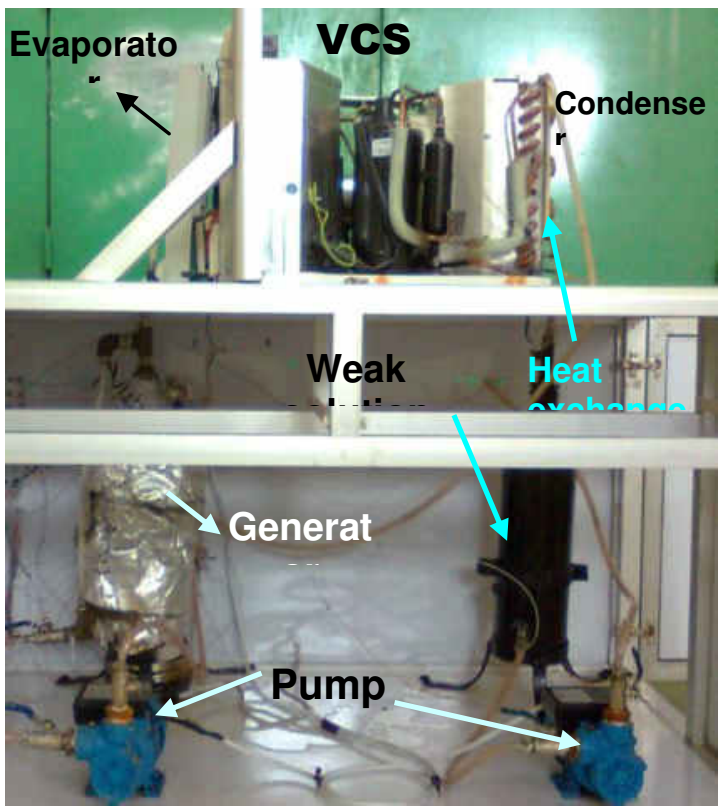

Fig. 3 Photograph of the HDAC system. 


\section{EXPERIMENTAL SETUP}

The experimental set-up of the proposed HDAC system is shown in Fig. 3. The heart of this system is the desiccant solution unit. A vapor compression unit is integrated with the desiccant solution unit. The VCS unit is a window DX type. The unit is 0.75 TR rating with $\mathrm{R}-134 \mathrm{a}$ as refrigerant. The desiccant solution unit uses lithium chloride solution as the working desiccant material. It consists of a weak and a strong solution tanks. A heating coil is wrapped around the strong solution tank (regenerator) and then insulated. Two pumps are used and some control valves to keep the strong and weak solutions flow rates equal.

Air and solution temperatures are measured using type $\mathrm{K}$ thermometers and a digital readout device with $0.1^{\circ} \mathrm{C}$ accuracy. Solution flow rates are measured using rotameters with $2 \%$ full scale accuracy. Solution density is measured using a very accurate digital scale ( $0.01 \mathrm{~g}$ accuracy) and is used to determine its concentration from $\mathrm{LiCl}$ properties table (at known temperature). Air velocity and humidity are measured using a multi-function hot wire measuring device with accuracy $0.015 \mathrm{~m} / \mathrm{s}$ for velocity and $3 \%$ for relative humidity. The power consumption is measured using a watt meter with $0.005 \mathrm{~kW}$ accuracy.

Experimental tests are carried out to evaluate the performance of the proposed multi-purpose HDAC system at different conditions. The following variables are measured: temperature and humidity of the process air at the inlet and exit of the evaporator section, ambient conditions, solution regeneration temperature, solution concentrations $\left(x_{4}\right.$ and $x_{8}$ ) and temperatures, temperature of air leaving condenser as well as evaporator and air velocity for both process and condenser air sides.

\section{PERFORMANCE ANALYSIS}

The following parameters are used to describe the performance of the proposed system. The proposed system coefficient of performance $C O P_{1}$ is calculated from

$$
C O P_{1}=m_{a}\left(h_{1}-h_{2}\right) / W
$$

where $W$ is the total power consumption.

$$
W=W_{c}+W_{A H}
$$

where $m_{a}$ is the mass flow rate of air, $h$ is the enthalpy of air, $W_{c}$ is the compressor power consumption, $W_{A H}$ is the auxiliary heat transfer rate for regeneration. Here, one $\mathrm{kW}$ of mechanical work energy is equal to three $\mathrm{kW}$ of thermal energy. This is because, in general, thermal energy is cheap and easy to get compared to mechanical work. Also this will visualize the potential benefits of the HDAC system especially in laboratory studies (using any available heat source). The VCS system with reheat has the following coefficient of performance

$$
\begin{aligned}
& C O P_{2}=m_{a}\left(h_{1}-h_{3}\right) /\left(W_{c}+Q_{\text {reheat }}\right) \\
& Q_{\text {reheat }}=m_{a}\left(h_{2}-h_{3}\right)
\end{aligned}
$$

The specific moisture recovery rate $S M R$ of the HDAC system is calculated from

$$
S M R=m_{a}(\Delta W) / m_{d}
$$


where $\Delta W$ is the specific humidity drop of the process air and $m_{d}$ is the mass flow rate of the desiccant solution. For the proposed HDAC system, the energy saving when using the condenser heat may be calculated from

$$
Q_{\text {preheat }}=m_{d} C_{p d}\left(T_{5}-T_{4}\right)
$$

where $C_{p d}$ is the specific heat of the desiccant solution. The auxiliary heat transfer rate for the generator may be obtained using a hot water coil (using waste heat recovery or solar heater) or any available source and accordingly the regeneration heat can be determined. Note that the absorber heat is removed by the evaporator.

\section{RESULTS AND DISCUSSION}

An experimental investigation to evaluate the effect of operating parameters on the performance of the proposed HDAC system has been carried out. The results of this experimental study are discussed below. In general, there are some comments that can be drawn from this study. The absorber is an integrated part with the evaporator and, therefore, its heat is removed by the cooling coil. Also, condensing the water vapor is done by the evaporator. These two heat rates may slightly affect the evaporator cooling capacity. But in general, the study showed a considerable improvement in the COP of the HDAC system compared to that of the VCS with reheat, as discussed later. On the other hand, the condenser heat is supplied at relatively lower temperature than that required for the regeneration process. The condenser heat transfer rate is always not enough for regeneration and therefore an auxiliary heat transfer rate is needed.

\section{1 effect of regeneration temperature}

Figure 4 represents sample temperature records of $T_{e v}, T_{a m b}, T_{c o n d}$ and $T_{\text {reg. }}$. They averaged nearly $14,20,45$ and $65^{\circ} \mathrm{C}$; respectively. Figs. 5, 6 and 7 show the effect of regeneration temperature $T_{\text {reg }}$ on the system $C O P_{1}, S M R$ and $x_{8}$; respectively. Fig. 5 shows that the $C O P_{l}$ increases with $T_{\text {reg }}$ until it reaches to nearly $65^{\circ} \mathrm{C}$, then it starts to decrease. This may be viewed as follows: the increases in $T_{\text {reg }}$ will directly increase the strong solution concentration and hence increasing the SMR as shown in Figs. 6 and 7. As $x_{8}$ of desiccant solution increases, the capacity of the solution to absorb moisture from air increases increasing the latent load capacity of the system. And as a result, the $\mathrm{COP}_{1}$ increases, but for further increase in regeneration temperature, the regeneration heat required at the same desiccant solution flow rate will increase. This will represent a penalty on $C O P_{1}$. By increasing the regeneration temperature from $65^{\circ} \mathrm{C}$ to $80^{\circ} \mathrm{C}$ (resulting in $23.1 \%$ increase in regeneration heat), the $C O P_{1}$ decreased by about $17.8 \%$ for an air mass flow rate of $0.321 \mathrm{~kg} / \mathrm{s}$ and a desiccant solution volume flow rate of 2.0 $\mathrm{L} / \mathrm{min}$. At the same conditions the SMR and $x_{8}$ will increase by about $7.15 \%$ and 28.6\%; respectively. Also, from Fig. 5 the $\mathrm{COP}_{1}$ directly increases with air mass flow rate due to the increase in the total cooling capacity. On the other hand from Fig. 7, by increasing the desiccant solution mass flow rate, the desiccant concentration $x_{8}$ is decreased at the same regeneration temperature. 


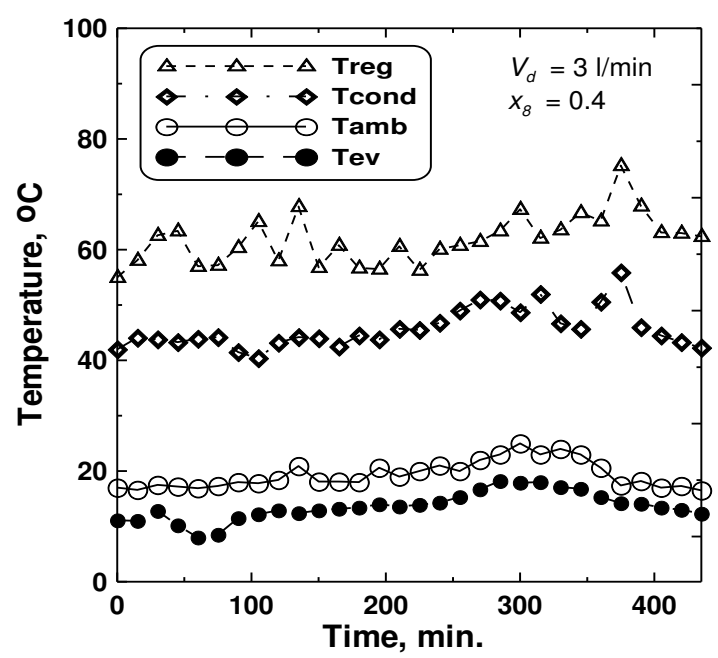

Fig. 4 HDAC temperature records.

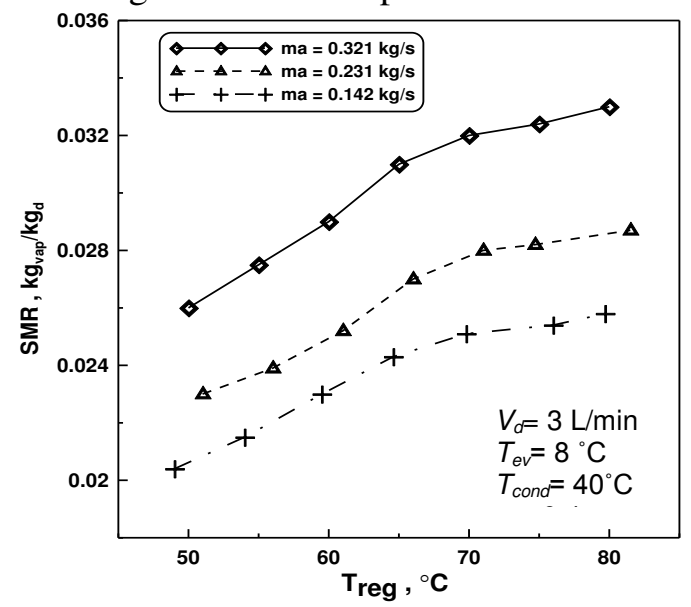

Fig. 6 Effect of $T_{\text {reg }}$ on $S M R$.

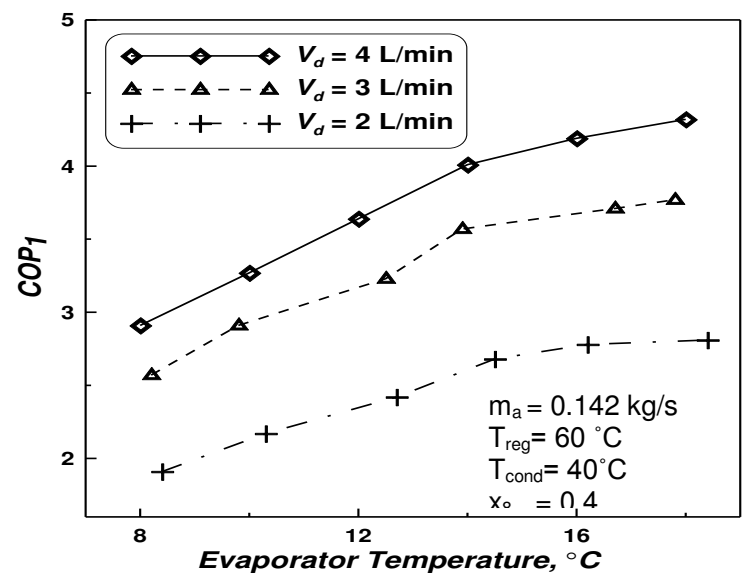

Fig. 8 Effect of evaporator temp. on $C O P_{l}$.

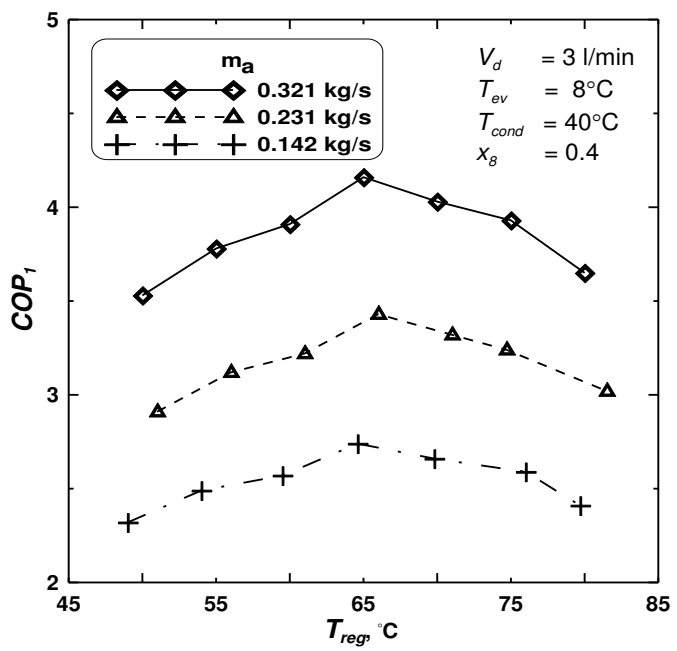

Fig. 5 Effect of Treg on COP1.

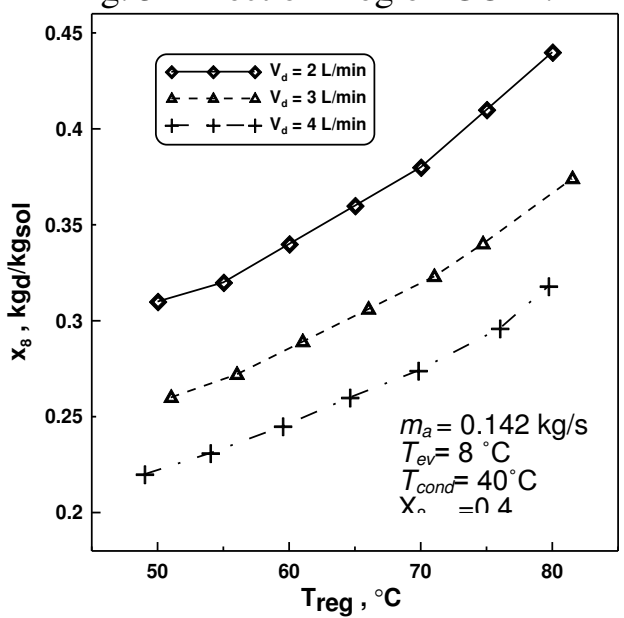

Fig. 7 Effect of $T_{\text {reg }}$ on strong sol. Concentration.

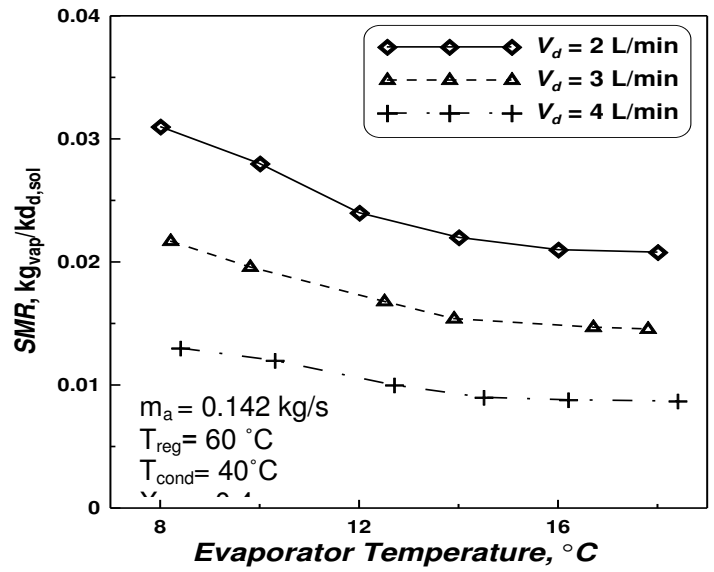

Fig. 9 Effect of evaporator temp. on SMR. 


\subsection{Effect of Evaporator Temperature}

Figures 8, 9 and 10 show the effect of evaporator temperature $T_{e v}$ on the HDAC system $C O P_{1}, S M R$ and $x_{4}$; respectively. Fig. 8 shows that the $C O P_{1}$ increases with $T_{e v}$ and with the desiccant solution volume flow rate $V_{d}$. By increasing $T_{e v}$ from $8^{\circ} \mathrm{C}$ to $18^{\circ} \mathrm{C}$ at $V_{d}=4 \mathrm{l} / \mathrm{min}, C O P_{1}$ will increases by about $41.2 \%$. On the other hand from Fig. 9, by increasing $T_{e v}$ from $8^{\circ} \mathrm{C}$ to $18^{\circ} \mathrm{C}$ at $V_{d}=41 / \mathrm{min}, S M R$ is decreased by about $33.3 \%$. As the evaporator temperature increases, the temperature of the strong solution sprayed over the evaporator will also increase decreasing the solution-air temperature difference. This will reduce the affinity of desiccant solution to recover moisture from process air and hence lowering the SMR. Fig. 10 shows the effect of $T_{e v}$ on weak solution concentration $x_{4}$. As $T_{e v}$ increases, the concentration $x_{4}$ is directly increased. By increasing $T_{e v}$ from $8^{\circ} \mathrm{C}$ to $18^{\circ} \mathrm{C}$ at $m_{a}=0.321 \mathrm{~kg} / \mathrm{s}, x_{4}$ is increased by about $19.8 \%$. This may emphasis the inability of the desiccant solution to catch moisture at higher solution temperature. The $C O P_{1}$ of the proposed system is found to be $68 \%$ greater than that of VCS with reheat as shown in Fig. 11. This may emphasis the potential benefits of using desiccant cooling technology.

Figure 12 shows the energy savings the proposed system vs. $T_{\text {reg. }}$. Maximum energy saving is achieved at $T_{\text {reg }}$ of about $65^{\circ} \mathrm{C}$ and increases as the air flow rate increase. An overall energy saving in the range of $30-43 \%$ is observed.

\subsection{Effect of Condenser Temperature}

Figures 13 and 14 show the effect of $T_{\text {cond }}$ on the system performance measures $C O P_{I}$ and $S M R$; respectively. By increasing $T_{\text {cond }}, C O P_{1}$ will directly decrease. This is because the increase of condenser temperature will increase the compressor power, which represents a penalty on $C O P_{1}$. On the other hand, $S M R$ increases with $T_{\text {cond }}$ until it reaches nearly $45^{\circ} \mathrm{C}$, it starts to decrease. By increasing $T_{\text {cond }}$ from $45^{\circ} \mathrm{C}$ to $50^{\circ} \mathrm{C}$, the SMR is decreased by about $13.6 \%$ at an air mass flow rate of $0.142 \mathrm{~kg} / \mathrm{s}$. This is partially referred to that increasing $T_{\text {cond }}$ will increase $T_{e v}$ and then reduces the ability of desiccant solution to absorb moisture from the process air.

\subsection{Effect of Strong Solution Concentration}

Figures 15 and 16 show the effect of strong solution concentration $x_{8}$ on the system $C O P_{1}$ and $S M R$; respectively. As $x_{8}$ increases, the $C O P_{1}$ and $S M R$ are increased. By increasing $x_{8}$, the affinity of desiccant solution to absorb moisture increases, leading to an observed increase in both $C O P_{1}$ and $S M R$. An increase of $x_{8}$ from 0.3 to 0.42 at an air mass flow rate of $0.321 \mathrm{~kg} / \mathrm{s}$ will increase the $C O P_{1}$ and $S M R$ by about 37.85 and $36 \%$; respectively.

\subsection{Effect of Desiccant Solution Flow Rate}

Figures 17 and 18 show the effect of desiccant solution flow rate $V_{d}$ on the system $S M R$ and water recovery rate $W R R$ at different air mass flow rates and regeneration temperatures; respectively. From Fig. 17, the $S M R$ reaches to $0.33 \mathrm{~g}_{\mathrm{vap}} / \mathrm{kg}_{\mathrm{sol}}$ at $V_{d}$ of 4 1/min. On the other hand the WRR is nearly about 6.7 1/h.TR at the same conditions. 
The curve fitting data for WRR at different $T_{\text {reg }}$ and $V_{d}$ is shown below. Note that the ranges of variables for Eqs. (7) and (8) are those found in Fig. 18.

$$
\begin{aligned}
& W R R=A_{0}+A_{1} V_{d}+A_{2} V_{d}^{2} \\
& A_{0}=0.04805142857 T_{\text {reg }}-4.522047619 \\
& A_{1}=-0.03248571429 T_{\text {reg }}+2.896990476 \\
& A_{2}=-0.001085714285 T_{\text {reg }}+0.3548571428
\end{aligned}
$$

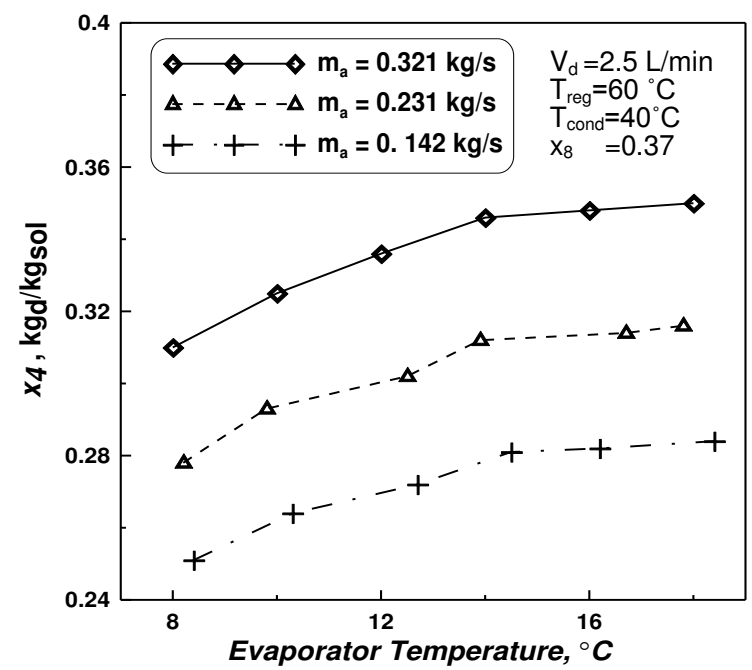

Fig. 10 Effect of $T_{e v}$ on $x_{4}$.

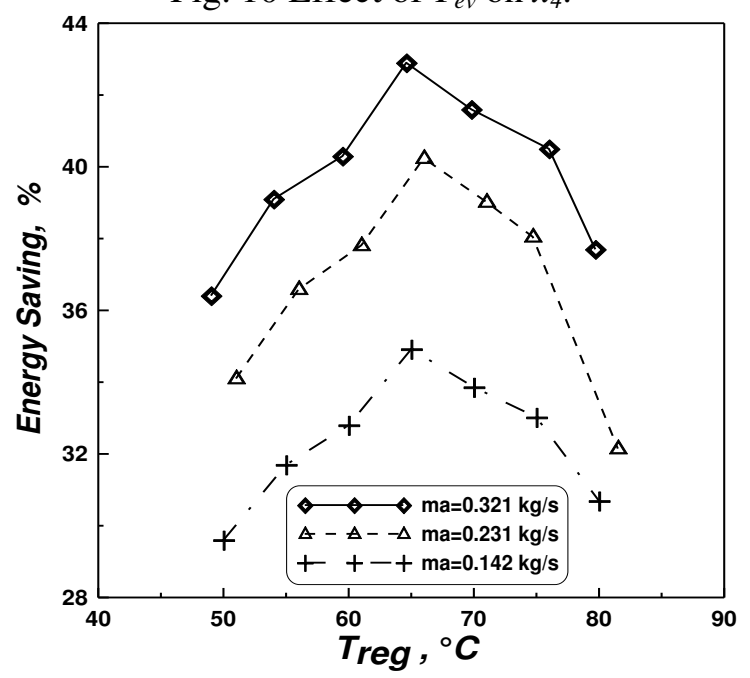

Fig. 12 Energy savings vs. $T_{\text {reg }}$.

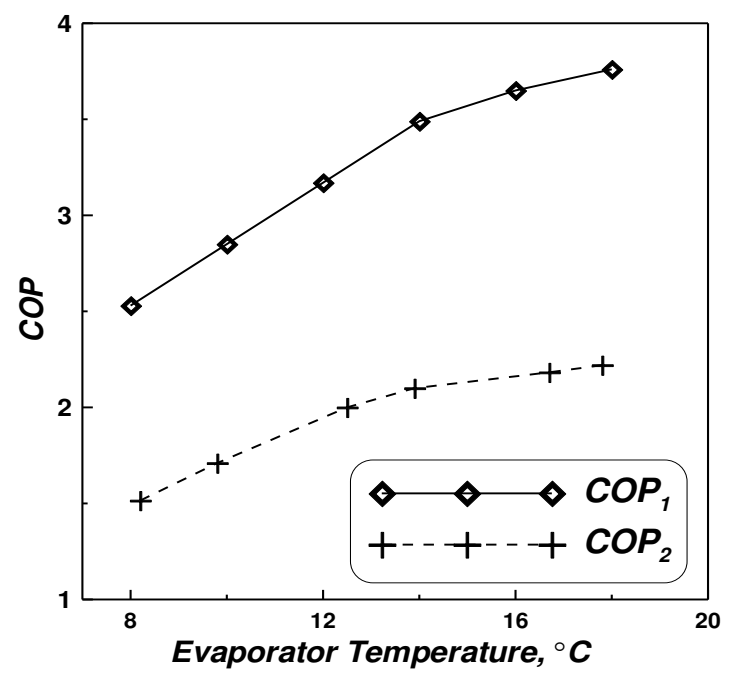

Fig. 11 Effect of evaporator temp. on $C O P$.

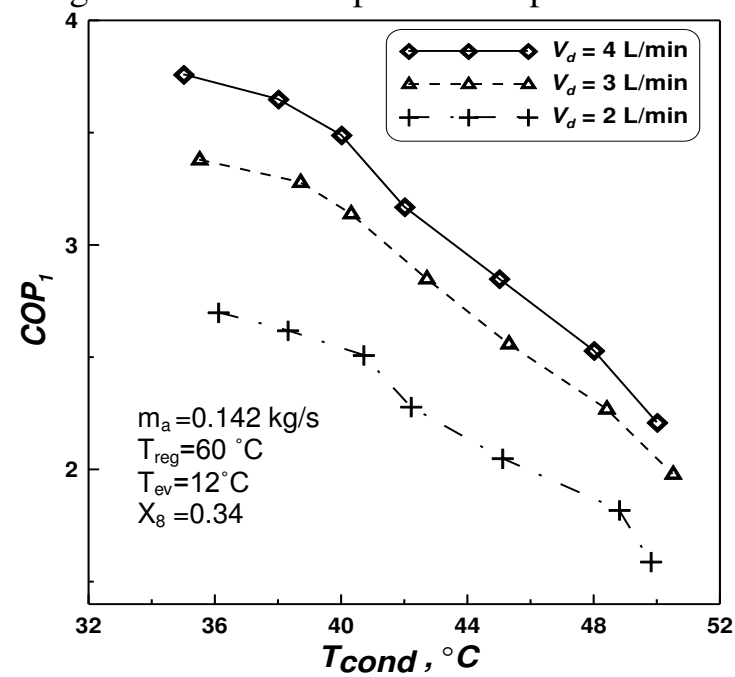

Fig. 13 Effect of $T_{\text {cond }}$ on $C O P_{1}$. 

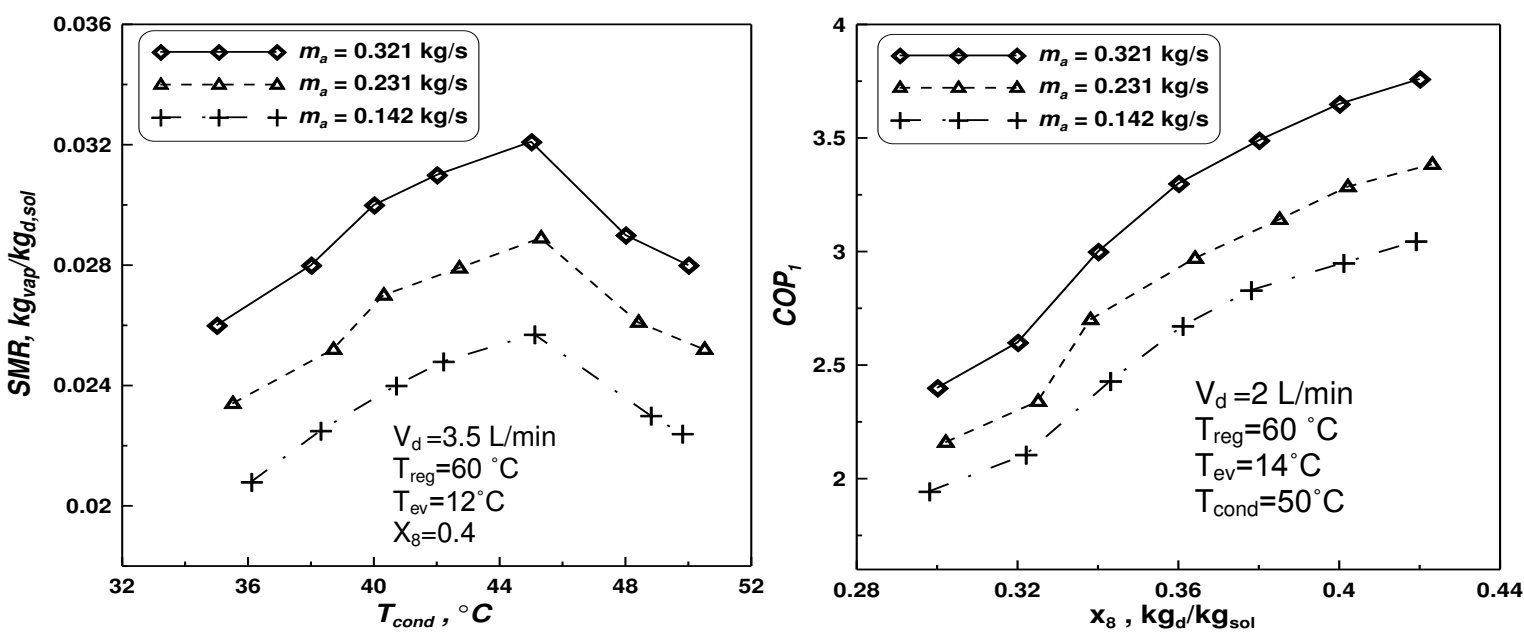

Fig. 14 Effect of $T_{\text {cond }}$ on $S M R$.

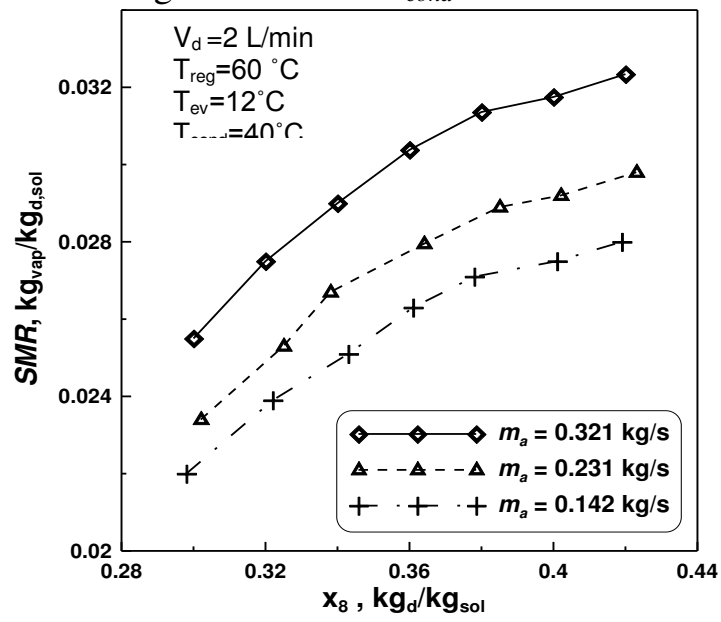

Fig. 15 Effect of $x_{8}$ on $\mathrm{COP}_{1}$.

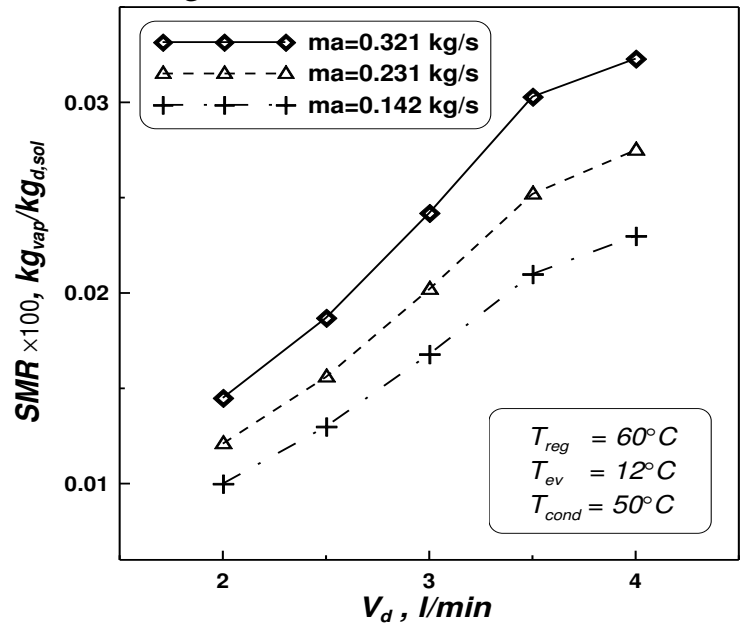

Fig. 16 Effect of $x_{8}$ on SMR.

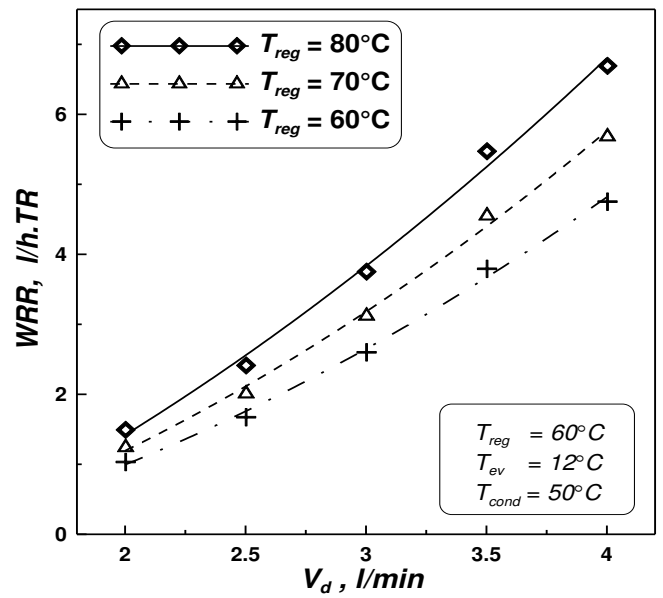

Fig. 18 Effect $V_{d}$ on WRR.

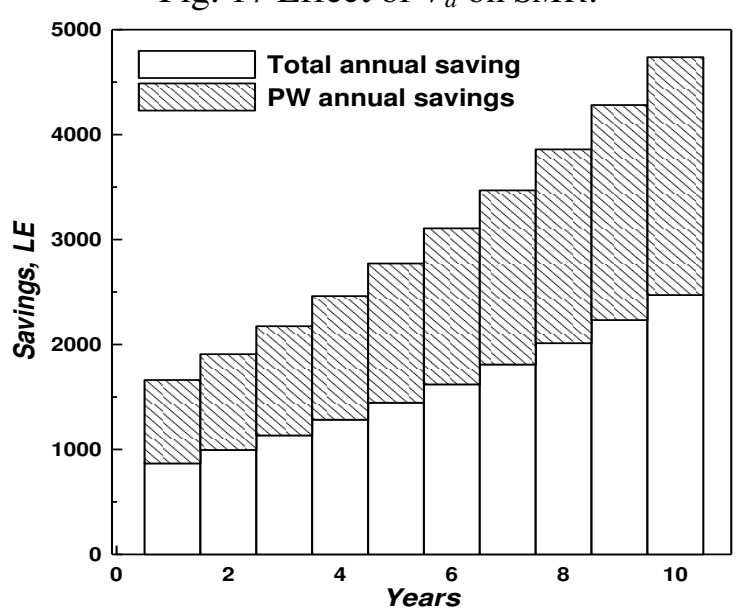

Fig. 19 Annual savings of energy cost and PW for the proposed system. 


\section{LIFE CYCLE COST ANALYSIS}

In this section the present worth value and the payback period are used to compare the proposed HDAC system and VCS system. The life cycle $N$ of the proposed system is assumed 10 years. The yearly loan (mortgage) payment for the proposed HDAC system can be calculated based on the present worth factor $P W F$ as follows [12]:

Mortgage payment $=$ Capital cost $/ P W F$

$$
\begin{aligned}
& P W F=\frac{1}{d-i}\left(1-\left(\frac{1+i}{1+d}\right)^{N}\right) \text { if } i \neq d \\
& P W F=\frac{N}{1+i} \text { if } i=d
\end{aligned}
$$

where $i$ is the energy interest rate and $d$ is the market discount rate. The life cycle savings $L C S$ (LE) may be calculated as follows:

$$
L C S=P W F \times \Delta C_{R C}-\Delta C_{I C}
$$

where $\Delta C_{R C}$ is annual running cost savings and $\Delta C_{I C}$ is the initial extra expenditure.

$$
\begin{aligned}
& \Delta C_{I C}=C_{I C, H D A C}-C_{I C, V C S} \\
& \Delta C_{R C}=C_{R C, V C S}-C_{R C, H D A C}
\end{aligned}
$$

A simple crude method for getting a quick evaluation of the alternatives is to calculate how long it takes to recover the initial investment, i.e. the payback period $P P$ as follows [13]

$$
P P=\ln \left(\frac{\Delta C_{I C} \times i}{\Delta C_{R C}}+1\right) / \ln (i+1)
$$

The total capital costs of the proposed HDAC and VCS with reheat system have been illustrated with the available material in the Egyptian market in Table 1. In both systems, window type VCS air conditioners are used as reflected in the capital costs below.

Table 1 Capital cost of both systems.

\begin{tabular}{|l|c|l|c|}
\hline \multicolumn{2}{|c|}{ HDAC System } & \multicolumn{2}{c|}{ VCS System with Reheat } \\
\hline & Cost, LE & \multicolumn{1}{c|}{ Cost, LE } \\
\hline DX unit (0.75 TR) & 1200 & DX unit (1.75 TR) & 3600 \\
\hline Lithium Chloride (2 kg) & 4000 & Reheat coil (added) & 800 \\
\hline Manufacturing and accessories & 1000 & Manufacturing and accessories & 450 \\
\hline Overheads & 300 & Overheads & 300 \\
\hline \multicolumn{1}{|c|}{ Total capital cost } & $\mathbf{6 5 0 0}$ & Total capital cost & $\mathbf{5 1 5 0}$ \\
\hline
\end{tabular}

The running cost of the HDAC and VCS system are calculated using a thermal energy weighting factor of three, (i.e. $1 \mathrm{kWh}$ of electrical energy $=3 \mathrm{kWh}$ of thermal energy). The price of one electric $\mathrm{kWh}$ is assumed to be $0.4 \mathrm{LE}$ in average, see Table 2. 
Table 2 Running cost of both systems.

\begin{tabular}{|l|c|c|l|l|r|}
\hline \multicolumn{3}{|c|}{ HDAC System } & \multicolumn{3}{|c|}{ VCS System with Reheat } \\
\hline & $\begin{array}{c}\mathrm{kWh} / \\
\text { day }\end{array}$ & $\begin{array}{c}\text { Annual, } \\
\text { LE }\end{array}$ & & $\begin{array}{c}\mathrm{kWh} / \\
\text { day }\end{array}$ & $\begin{array}{c}\text { Annual, } \\
\text { LE }\end{array}$ \\
\hline $\begin{array}{l}\text { Regeneration heat }(0.58 \\
\mathrm{kW})\end{array}$ & 5.22 & 417.6 & Reheat coil $(2.0 \mathrm{~kW})$ & 18.00 & 1440.0 \\
\hline $\begin{array}{l}\text { Compressor and fans } \\
(1.14 \mathrm{~kW})\end{array}$ & 10.26 & 820.8 & $\begin{array}{l}\text { Compressor and fans } \\
(1.95 \mathrm{~kW})\end{array}$ & 17.55 & 1404.0 \\
\hline Maintenance & & 200.0 & Maintenance & & 200.0 \\
\hline $\begin{array}{c}\text { Total annual running } \\
\text { cost }\end{array}$ & $\mathbf{1 5 . 4 8}$ & $\mathbf{1 4 3 8 . 4}$ & $\begin{array}{c}\text { Total annual running } \\
\text { cost }\end{array}$ & $\mathbf{4 0 . 8 6}$ & $\mathbf{3 0 4 4}$ \\
\hline
\end{tabular}

The difference in capital cost $\Delta C_{I C}$ is $1350 \mathrm{LE}$ as shown in Table 1 and the difference in annual running cost $\Delta C_{R C}$ is $1605.6 \mathrm{LE}$ as shown in Table 2. The capital cost of the hybrid system is financed over 10 years at market discount rate $d=9 \%$ and the annual cost payments are expected to inflate at a rate of $i=8 \%$. From Eq. (15) the mortgage payment is equal to $6500 / 8.8=738 \mathrm{LE}$. Also, the payback time is found to be 0.84 years ( 10 months). The payback time of the proposed system is less than one year and it will achieve an annual savings in the total running cost of about 53\% compared to VCS with reheat. The total annual saving of the HDAC system reaches $2470 \mathrm{LE}$ at the end of its life time. Due to the market discount rate, the annual present worth value is expected to be 2260 LE compared to the conventional VCS with reheat system. Fig. 20 shows a diagram for the annual total savings and the present worth savings. Note: the total capital cost of the HDAC system as shown in Table 1 is almost the same as that of the VCS with reheat that uses an air conditioner of the conventional split type.

\section{CONCLUSIONS}

A multi-purpose HDAC integrated vapor compression system of a small capacity is designed and experimentally tested. At specific design and operating conditions, some important conclusions can be summarized as follows:

- The $C O P_{1}$ and $S M R$ are both increased with air mass flow rate and desiccant flow rate.

- An increase of strong solution concentration will increase the $C O P_{1}$ and $S M R$.

- By increasing $T_{e v}$; the $C O P_{l}$ increases but $S M R$ decreases.

- By increasing the $T_{\text {reg }}$; the $C O P_{l}$ decreases and $S M R$ increases.

- Results showed that an amount of $6.7 \mathrm{l} / \mathrm{h}$.TR of pure water can be collected at specific design and operating conditions.

- An imperical relation for the $W R R$ with $V_{d}$ and $T_{r e g}$ is withdrawn.

- The $C O P_{1}$ of the proposed system is found to be $68 \%$ greater than that of VCS with reheat at typical operating conditions.

- The HDAC system can achieve an annual energy savings of 53\% and has apayback period of 10 months compared to the $V C S$ with reheat.

- A HDAC system integrated with a 0.75-TR conventional air conditioner can replace a VCS with reheat with a cooling capacity of 1.75 TR in addition to a reheat coil of $2.0 \mathrm{~kW}$ rating. 


\section{REFERENCES}

1. Mei, L. and Y. J. Dai, A technical review on use of liquid-desiccant dehumidification for air-conditioning application, Renewable and Sustainable Energy Reviews, Vol. 12, pp. 662-689, 2008.

2. Adnan, K.K., M. M. Elsayed and M.O. Alraghi., Proposed Energy Efficient Air Conditioning System Using Liquid Desiccant, Applied Thermal Engineering, Vol. 16, pp. 791-806, 1996.

3. Mohan, B., M. Shaji, P. Maiya and S. Tiwar, Performance Characterization of Liquid Desiccant Columns for a Hybrid Air-Conditioner, Applied Thermal Engineering, Vol. 28, pp. 1342-1355, 2008.

4. Jia, C.X., Y.J. Dai, J.Y. Wu and R.Z. Wang, Analysis on a Hybrid Desiccant AirConditioning System, Applied Thermal Engineering, Vol. 26, pp. 2393-2400, 2006.

5. Ahmed, C.S., P. Gandidasan and A.A. Al-Farayedhi, Simulation of A Hybrid Liquid Desiccant Based Air-Conditioning System, Applied Thermal Engineering, Vol. 17, pp. 125-134, 1997.

6. Yadav, Y.K., Vapor-compression and liquid-desiccant hybrid solar spaceconditioning system for energy conservation, Renewable Energy, Vol. 6, pp. 719723, 1995.

7. Yadav, Y.K., S.C. Kaushik, Psychometric Techno-Economic Assessment and Studies of Vapor-Compression and Solid/Liquid Desiccant Solar Space Conditioning Systems, Heat Recovery Systems and CHP, Vol. 11, pp. 563-572, 1991.

8. Dai, Y.J., R.Z. Wang, H.F. Zhang and J.D. Yu, Use of Liquid Desiccant Cooling to Improve the Performance of Vapor Compression Air Conditioning, Applied Thermal Engineering, Vol. 21, 1185-1202, 2001.

9. Burns P.R., J.W. Mitchell, W.A. Beckman, Hybrid desiccant cooling systems in super market applications, ASHRAE Trans. Vol. 91, Part-1B, pp. 457-468, 1985.

10. Close D.J. and J.C. Sheridan, Low energy cooling for humid regions, Australian Institute of Refrigeration Air Conditioning and Heating (AIRAH) Federal conference, Tasmania, 1982.

11. Singh, S.K., S. Jain and S.C. Kaushik, Energy Conservation through Hybrid Air Conditioning Cycles: Computer Modeling Studies, technical report, IIT, Delhi, 1996.

12. Nesreen, G., G. Kamel and N. Antoine, "Use of desiccant dehumidification to improve energy utilization in air-conditioning system in Beirut", Int. J. Energy Res. 2003, 27: 1317:1338.

13. Duffie, J. A. and W. A. Beckman, "Solar Engineering of Thermal Processes" a Wiley Inter science, New York, 1974. 


\section{دراسة عملية لنظام تكييف هواء متعدد الأغراض يعمل بالمواد \\ المازة مدمج مع دورة إنضغاط البخار}

\section{د/ السعيد خليل - عضو ASHRAE \\ أستاذ مساعد بقسم هندسة القوى الميكانيكية - كلية الهندسة - جامعة طنطا \\ akhalileg@yahoo.com}

يتتاول هذ البحث دراسة عملية لنظام تكييف هواء هجين متعدد الأغراض يعمل بالمواد المازة السائلة المدمجة مع دورة إنضغاط البخار • تم تصميم المنظومة - المسماة إختصارا HDAC - لتلبية منطلبات لهات أحمال النتريد لتكييف هواء فراغات ذات حمل كامن عالى نسبيا بالإضافة إلى إستخلاص الماء العذب العباء

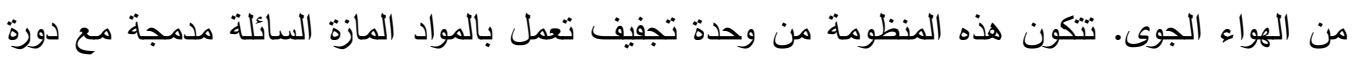

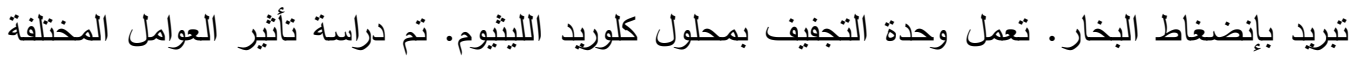
على أداء المنظومة، مثل معدل سريان محلول كلوريد الليثيوم، ومعدل سريان الهواء المكيف، ودرجات حرارة كل من المبخر والمكثف، وتركيز المحلول المركز ودرجة حرارة عملية التنشيط. يمكن لمنظومة HDAC إستخلاص 6.7 لتر/ساعة-طن تبريد من الماء العذب من الهواء الجوى. وحققت المنظومة معامل أداء يصل إلى 3.8 بزيادة مقدارها 68\% عن دورة إنضغاطهاط البخار التقليدية. إستطاعت المنظومة تغطية حمل تبريد مقداره 1.75 طن تبريد بإستخدام دورة إنضغاط البخار قدرتها الإسمية 0.75 طن تبريد. وأخيرا فإن المنظومة بما تحققه من وفر فى الطاقة تنتطيع إسترداد تكلفتها

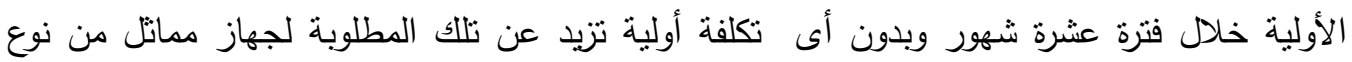

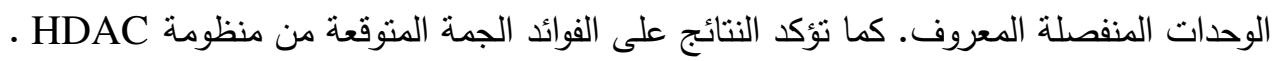

